\title{
A New Development of BQS (Blastability Quality System) for Closely Spaced Formations
}

\author{
Maria Chatziangelou and Basile Christaras \\ Department of Geology, Aristotle University of Thessaloniki, Thessaloniki 54631, Greece
}

\begin{abstract}
Success in the excavation of geological formations is commonly known as being very important in asserting stability. Furthermore, when the subjected geological formation is rocky and the use of explosives is required, the demands of successful blasting are multiplied. The present paper proposes a classification system, named: BQS (Blastability Quality System), for rock masses with closely spaced discontinuities (spacing lower than $0.1 \mathrm{~m}$ ). It is obvious that rock quality is one of the main characteristics which define the blast ability of a rock. The BQS can be an easy and widely-used tool as it is a quick evaluator for blastability and rock mass quality at one time. Taking into consideration the research calculations and the parameters of BQS, what has been at question in this paper is the effect of blast ability in a geological formation with closely spaced discontinuities.
\end{abstract}

Key words: Geological classification, blast ability, rock mass, quality, methodology.

\section{Introduction}

The several geological formations, which are affected by numerous stages of disintegration in varying stress conditions, may act in a different manner under specified blast design, explosive characteristics and specified legislative constraints depending on the site specifics.

The present paper improves "BQS (Blastability Quality System)" [1] by combining the quality with the blast ability of a rock mass [2], which can be easily used in situ, in order to estimate, easily, the explosion results [3] in relation to the excavation methods. The geological provision of explosion results and the ability of engineering geologists or engineers to choose quickly, the most applicable way of blasting, minimize, in the same time, the percentage of instability problems. Taking into account the extent of stability problems on places stricken by earthquake, where damage incurred over the years has indicated that many reinforced concrete buildings, were found to have serious structural deficiencies, especially in their columns and

Corresponding author: Chatziangelou Maria, research collaborator, research fields: engineering geology and tunneling. beam - column joints [4], the use of blasting and explores needs extra attention.

Referring to the blasting to the excavation, the study takes into consideration the cohesive soil and laminated formations which cannot be excavated by mechanical means easily.

\section{Theory}

2.1 Rock Mass Quality Using RMR (Rock Mass Rating) Classification System

RMR (Rock Mass Rating) classification system [5] is based on mechanical and structural characteristics of rock mass. The RMR index is calculated:

$$
\mathrm{RMR}=\mathrm{A} 1+\mathrm{A} 2+\mathrm{A} 3+\mathrm{A} 4+\mathrm{A} 5+\mathrm{B}
$$

Where $\mathrm{A} 1=$ rating for the uniaxial compressive strength of the rock material, $\mathrm{A} 2$ = rating for the drill core quality RQD, $\mathrm{A} 3$ = ratings for the spacing of joints, $\mathrm{A} 4=$ ratings for the condition of joints, A5 = ratings for the ground water conditions, and $\mathrm{B}=$ ratings for the orientation of joints.

From the value of RMR in the actual excavation, the rock support can be estimated. RMR can be used to crudely estimate the deformation modulus of rock masses, too. Bieniawski [5] strongly emphasizes that a 
great deal of judgment is used in the application of a rock mass classification system in support design [6].

In the RMR system, there is no input parameter for rock stresses, but stresses up to $25 \mathrm{MPa}$ are included in the estimated RMR value. Thus, overstressing (rock bursting and squeezing) is not included. Whether of how faults and weakness zones are included, is unclear. No special parameter for such features is used, but some of the parameters included in the system may represent conditions in faults, though the often complicated structure and composition in these features are generally difficult to characterize or classify. Therefore, it is probable that RMR does not work well for many faults and weak zones. Swelling rock is not included in the RMR system [7].

\subsection{Geological Strength Index}

The GSI (Geological Strength Index) [8] relates to the overall rock mass quality. It is based on an assessment of the lithology, structure and condition of discontinuous surfaces in the geological foundations and is estimated through visual examination of rock mass exposed in crops, surface excavations such as road cuts, tunnel faces or borehole cores. It utilizes two fundamental parameters of the geological process (block size of the mass and discontinuities characteristics); hence it takes into consideration the main geological constraints that govern a formation. In addition, the index is simple to assess in the earth field.

According to Palmstrom [9], block size and discontinuity spacing can be measured by means of the Volumetric Joint Count $\mathrm{J}_{\mathrm{v}}$, or by means of block volume, $\mathrm{V}_{\mathrm{b}}$. Sommez and Ulusay [10] quantified block size in the GSI chart by the SR (Structure Rating) coefficient that is related to the $\mathrm{J}_{\mathrm{v}}$ coefficient. Cai et al. [11] presented a quantifier by the mean of discontinuity spacing $S$ of by the mean block volume $V_{b}$. The structure was quantified by joint spacing in order to calculate the block volume, and the joint surface condition was quantified by a joint condition factor. The GSI is therefore built on the linkage between descriptive geological terms and measurable earth field parameters such as joint spacing or roughness. So, based on the above information, GSI uses the description of rock mass structure - as laminated and sheared, disintegrated, blocky and disturbed, very blocky, blocky and intact of massive - referring to the block size and discontinuity space and the description of surface conditions - or as very poor, poor, fair, good and very good — referring to the joint surface conditions.

The rock mass type is a controlling factor in the assessment of the earth excavation method, as it is closely related to the number of discontinuity sets and reflects the rock mass structure. The GSI, in its original form, was not scale dependent, thus the block size is not directly related to the rock mass type. Nevertheless, each rock type has a broad correlation to the rock block size, i.e., a rock mass which is characterized as "blocky" has bigger blocks than a rock mass which is characterized as "very blocky" or "disintegrated", that is, made up of very small rock fragments. The sheared schist, as the spacing of the schistosity planes equates to the discontinuity planes and hence the concept of block volume is not applicable. The present classification for the assessment of excavation ability is based on the original GSI charts (version 2000).

Hoek and Karzulovic [12] suggested a range of GSI values for different excavation methods. They proposed that rock masses can be dug up when GSI is estimated to be about 40 and the rock mass strength is about $1 \mathrm{MPa}$, while ripping can be used when GSI is estimated between 40 and 60 and rock mass strength is about $10 \mathrm{MPa}$. Blasting was the only effective excavation method when GSI is greater than 60 and rock mass strength is more than $15 \mathrm{MPa}$.

\subsection{Blastability Index Concerning Rock Mass Classification Systems}

The factors that influence blasting results fall into two groups. The first group concerns the intact rock properties, which includes strength, hardness, elasticity, deformability, density of rock, etc. The qualities 
depend on texture, internal bonds, composition and distribution of minerals in the geological foundation. The second group concerns the discontinuity structure, which includes the orientation, spacing, the extent of discontinuities, and the in-situ block sizes created by a range of long-term geological processes.

The BI (Blastability index) is a quantitative measure of the blastability of a rock mass. It will be most advantageous for the BI to be determined before blasting in order to help with the blast design of an excavation. Without any realistic chance in the short term of a practical analytical solution to define the value of the BI for a given rock mass as a function of material properties, the development of a comprehensive assessment system for quantifying the blastability of geological masses would appear to have great potential [13].

$\mathrm{BI}$ is used for the description of the ease of blasting and it is also related to rock fragmentation [14] or power factor. When the $\mathrm{BI}$ is lower than 8 , the ease of blasting is described as "very difficult". When the BI range is between 8 and 13 , the ease of blasting is described as "difficult". When the BI range is between 13 and 20 , the ease of blasting is described as "moderate". When the BI range is between 20 and 40, the ease of blasting is described as "easy". When the BI is higher than 40 , the ease of blasting is described as "very easy". This differentiation in description has an immediate effect on excavation cost which always depends on factors like explosion, vibration, disintegration, powder creation etc. [15].

In our study, the BI is to be calculated by the following formula which is proposed by Lilly [16], based on rock mass description, joint density and orientation, specific gravity and hardness:

$$
\mathrm{BI}=0.5 \times(\mathrm{RMD}+\mathrm{JPS}+\mathrm{JPO}+\mathrm{SGI}+\mathrm{H})
$$

Where,

$\mathrm{BI}=$ Blastability Index

RMD (Rock mass Description) $=$

10, for Powdery/Friable rockmass

20, for Blocky rockmass
50, for Totally Massive rockmass

JPS (Joint Plan Spacing) =

10, for Closely Spaced discontinuities $(<0.1 \mathrm{~m})$

JPO (Joint Plane Orientation $)=$

10, for Horizontal

20, for Dip out of the Face

30, for Strike Normal to Face

40, for Dip into Face

SGI $=$ Specific Gravity Influence $=$

$25 \times$ Specific Gravity of rock $\left(\mathrm{t} / \mathrm{m}^{3}\right)-50$

$\mathrm{H}=$ Hardness in Mho Scale between 1 and 10

Considering that blastability index, as it is calculated by Lilly's formula, is based on geological formation description, joint density and orientation, evokes the same parameters that Rock Mass Rating System-RMR is also based on.

The above classification can be described by GSI, too.

\section{Results}

\subsection{Combining Blastability with the Rock Mass Quality}

The laminated and sheared rock mass, with lack of blockiness due to closely spaced discontinuities of week schistosity or shear planes and disintegrated rock mass, with poorly interlocked, heavily broken rock with mixture of angular or rounded rock pieces, which are described by the lower part of GSI diagram, has been divided into eight parts: A, B, C, D, E, F, G, H (Fig. 1). The disturbed, seamy and very blocky rock mass, folded with angular blocks formed by many intersecting discontinuity sets with bedding planes or schistosity, in addition to interlocked, partially disturbed mass with multi-faceted angular blocks formed by four or more joint sets, which are described by the middle part of GSI diagram, has been divided into ten parts: I, J, K, L, M, N, O, P, Q, R (Fig. 1). The well interlocked undisturbed blocky rock mass, which consists of cubical blocks formed by three intersecting discontinuity sets, which is described by the above part of GSI diagram, has been divided into five parts: S, T, U, V and W (Fig. 1). 


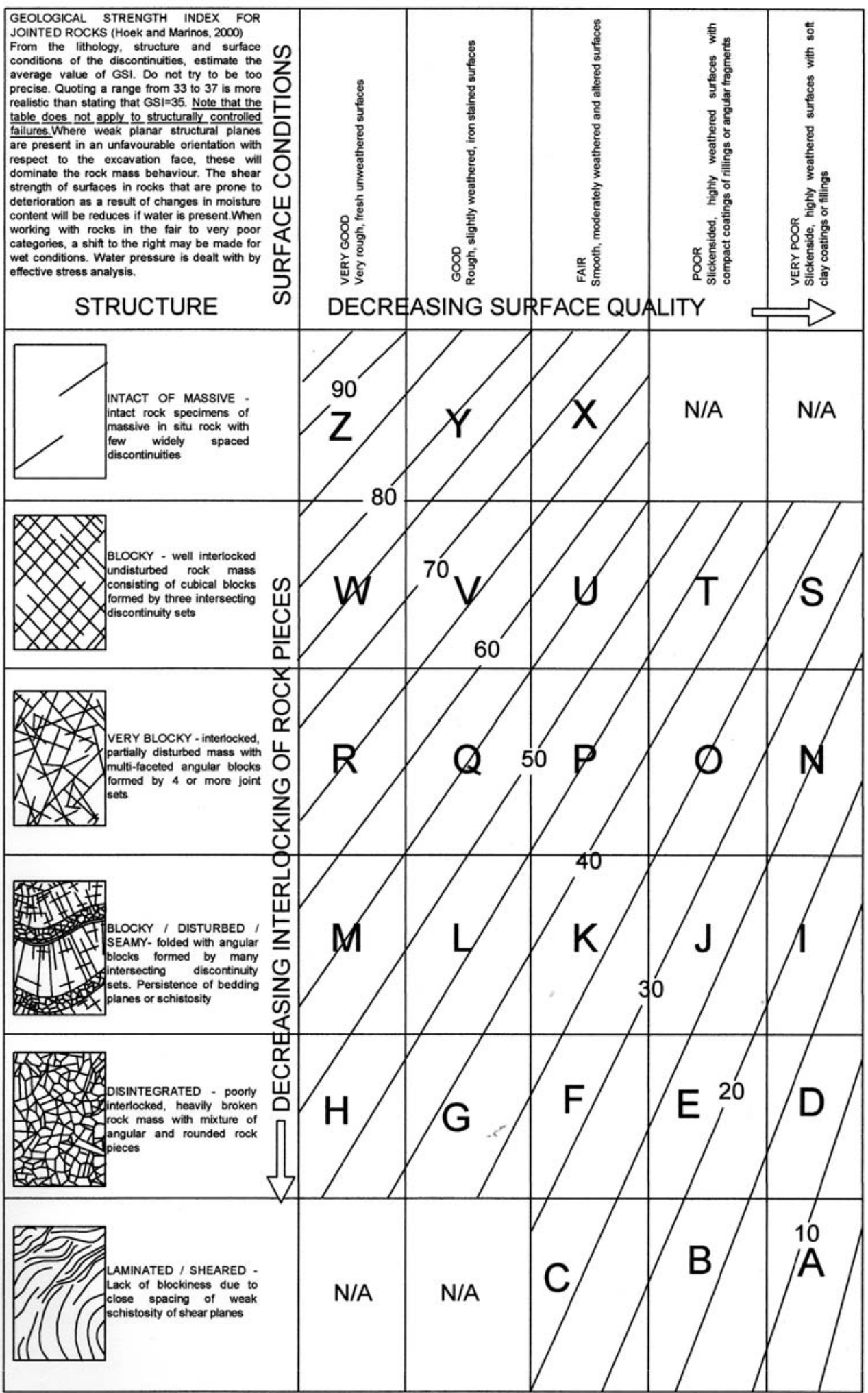

Fig. 1 Division of GSI diagram.

Taking into consideration the parameters of Blastability Index-BI $=0.5 \times(\mathrm{RMD}+\mathrm{JPS}+\mathrm{JPO}+$
SGI $+\mathrm{H})$ - (11), the BI was calculated for every possible combination of these parameters. This means 
that RMD was equal to 10 for powdery/friable rock mass and 20 for blocky rock mass. As the present study concerns closely spaced discontinuities, JPS (joint plan spacing) was equal to 10 for closely spaced. JPO (joint plane orientation) was equal to 10 for horizontal discontinuities, 20 for declined discontinuities where the excavation drives against dip direction, 30 for declined discontinuities with strike parallel to face, 40 for declined discontinuities where the excavation drives with dip direction and SGI (specific gravity influence) was calculated using specific gravity of rocks $\left(\mathrm{t} / \mathrm{m}^{3}\right)$ from 1-3 (Table 1). 1,600 different rock mass combinations were estimated (Table 2 ).

The parameters of the BI calculation are also presented in Table 2, numbering the rock mass types from 1 to 1,600 . At next stage, we regrouped the above rock structures referring to RMR range and GSI parts, taking into consideration rock mass hardness and discontinuities orientation. The range of BI was also calculated (Tables 3-6). GSI range was calculated for every rock mass type with a specific RMR. The rock

Table 1 Specific gravity influence (SGI).

\begin{tabular}{ll}
\hline $\begin{array}{l}\text { SGI } \\
\begin{array}{l}\text { T } 5 \times \text { specific gravity of rock } \\
\left(\mathrm{t} / \mathrm{m}^{3}\right)-50\end{array}\end{array}$ \\
\hline-22.5 & Specific gravity of rock $\left(\mathrm{t} / \mathrm{m}^{3}\right)$ \\
-20 & 1.1 \\
-17.5 & 1.2 \\
-15 & 1.3 \\
-12.5 & 1.4 \\
-10 & 1.5 \\
-7.5 & 1.6 \\
-5 & 1.7 \\
-2.5 & 1.8 \\
0 & 1.9 \\
2.5 & 2 \\
5 & 2.1 \\
7.5 & 2.2 \\
10 & 2.3 \\
12.5 & 2.4 \\
15 & 2.5 \\
17.5 & 2.6 \\
20 & 2.7 \\
22.5 & 2.8 \\
25 & 2.9 \\
\hline
\end{tabular}

structures are numbered from 1 to 1,600 and they were banded together according to RMR range, too. In Table 3 GSI parts are equivalent to RMR range.

In Tables 4-6, blastability index for these grouped rock structures appears in addition to GSI parts. On the same tables RMR range is equivalent to GSI parts.

Finally, a useful diagram of composite rock mass quality and range of the BI aroused from the above estimations (Fig. 2). The rock mass may consist of horizontal or gradient discontinuities with strike perpendicular to tunnel axis or strike parallel to tunnel axis. In case there are only horizontal discontinuities, the blastability index was calculated between 4 and 37 for disintegrated and laminated rock mass and between 9 and 37 for blocky rock mass. That means blasting is very difficult for soft disintegrated and laminated rock mass and difficult for soft blocky rock mass. But as the rock mass hardness is higher, blasting is easier. In case the discontinuities are gradient and the strike of formation is parallel to tunnel axis, the blastability index was calculated between 14 and 42 for disintegrated and laminated rock mass and between 19 and 47 for blocky rock mass. Blasting is characterized as moderate, for soft rock mass, to very easy, for hard rock mass. In case of gradient discontinuities and rock mass may strike perpendicular to excavation axis when excavation drives against dip direction, the blastability index was calculated between 4 and 37 for disintegrated and laminated rock mass and between 14 and 42 for blocky rock mass. So, blasting is characterized as very difficult (soft rock mass) to easy (hard rock mass) for disintegrated and laminated rock mass and moderate (soft rock mass) to easy (hard rock mass) for blocky rock mass. In case of gradient discontinuities and rock mass may strike perpendicular to excavation axis when excavation drives with dip direction, the blastability index was calculated between 19 and 47 for disintegrated and laminated rock mass and between 24 and 52 for blocky rock mass. So, blasting is characterized as moderate (soft rock mass) to very easy (hard rock mass) for disintegrated and 
Table 2a BI calculations for closely spaced discontinuities.

\begin{tabular}{|c|c|c|c|}
\hline$\alpha / \alpha$ & RMD & JPS & JPO \\
\hline $001-20$ & 10 & 10 & 10 \\
\hline $21-40$ & 10 & 10 & 10 \\
\hline $41-60$ & 10 & 10 & 10 \\
\hline $61-80$ & 10 & 10 & 10 \\
\hline $81-100$ & 10 & 10 & 10 \\
\hline $101-120$ & 10 & 10 & 10 \\
\hline $121-140$ & 10 & 10 & 10 \\
\hline $141-160$ & 10 & 10 & 10 \\
\hline $161-180$ & 10 & 10 & 10 \\
\hline $181-200$ & 10 & 10 & 10 \\
\hline $201-220$ & 10 & 10 & 20 \\
\hline $221-240$ & 10 & 10 & 20 \\
\hline $241-260$ & 10 & 10 & 20 \\
\hline $261-280$ & 10 & 10 & 20 \\
\hline $281-300$ & 10 & 10 & 20 \\
\hline $301-320$ & 10 & 10 & 20 \\
\hline $321-340$ & 10 & 10 & 20 \\
\hline $341-360$ & 10 & 10 & 20 \\
\hline $361-380$ & 10 & 10 & 20 \\
\hline $381-400$ & 10 & 10 & 20 \\
\hline $401-440$ & 10 & 10 & 30 \\
\hline $421-440$ & 10 & 10 & 30 \\
\hline $441-460$ & 10 & 10 & 30 \\
\hline $461-480$ & 10 & 10 & 30 \\
\hline $481-500$ & 10 & 10 & 30 \\
\hline $501-520$ & 10 & 10 & 30 \\
\hline $521-540$ & 10 & 10 & 30 \\
\hline $541-560$ & 10 & 10 & 30 \\
\hline $561-580$ & 10 & 10 & 30 \\
\hline $581-600$ & 10 & 10 & 30 \\
\hline $601-620$ & 10 & 10 & 40 \\
\hline $621-640$ & 10 & 10 & 40 \\
\hline $641-660$ & 10 & 10 & 40 \\
\hline $661-680$ & 10 & 10 & 40 \\
\hline $681-700$ & 10 & 10 & 40 \\
\hline
\end{tabular}

laminated rock mass and easy (soft rock mass) and very easy (hard rock mass) for blocky rock mass. All in all, according to the surface conditions and the structure of the rock mass, we can estimate GSI and RMR range. According to the estimated BI values, blasting is characterized of a relative easyness, according to rock mass quality and hardness. A detailed evaluation of blastability index for every rock mass structure type is given in Fig. 2, so as the rock mass is classified according to rock mass quality and hardness. A detailed

\begin{tabular}{lll}
\hline SGI & H & BI \\
\hline From -22.5 to 25 & 1 & $4.25-28$ \\
From -22.5 to 25 & 2 & $4.75-28.5$ \\
From -22.5 to 25 & 3 & $5.25-29$ \\
From -22.5 to 25 & 4 & $5.75-29.5$ \\
From -22.5 to 25 & 5 & $6.25-30$ \\
From -22.5 to 25 & 6 & $6.75-30.5$ \\
From -22.5 to 25 & 7 & $7.25-31$ \\
From -22.5 to 25 & 8 & $7.75-31.5$ \\
From -22.5 to 25 & 9 & $8.25-32$ \\
From -22.5 to 25 & 10 & $8.75-32.5$ \\
From -22.5 to 25 & 1 & $9.25-33$ \\
From -22.5 to 25 & 2 & $9.75-33,5$ \\
From -22.5 to 25 & 3 & $10.25-34$ \\
From -22.5 to 25 & 4 & $10.75-34.5$ \\
From -22.5 to 25 & 5 & $11.25-35$ \\
From -22.5 to 25 & 6 & $11.75-35.5$ \\
From -22.5 to 25 & 7 & $12.25-36$ \\
From -22.5 to 25 & 8 & $12.75-36.5$ \\
From -22.5 to 25 & 9 & $13.25-37$ \\
From -22.5 to 25 & 10 & $13.75-37.5$ \\
From -22.5 to 25 & 1 & $14.25-38$ \\
From -22.5 to 25 & 2 & $14.75-38.5$ \\
From -22.5 to 25 & 3 & $15.25-39$ \\
From -22.5 to 25 & 4 & $15.75-39.5$ \\
From -22.5 to 25 & 5 & $16.25-40$ \\
From -22.5 to 25 & 6 & $16.75-40.5$ \\
From -22.5 to 25 & 7 & $17.25-41$ \\
From -22.5 to 25 & 8 & $17.75-41.5$ \\
From -22.5 to 25 & 9 & $18.25-42$ \\
From -22.5 to 25 & 10 & $18.75-42.5$ \\
From -22.5 to 25 & 1 & $19.25-43$ \\
From -22.5 to 25 & 2 & $19.75-43.5$ \\
From -22.5 to 25 & 3 & $20.25-44$ \\
From -22.5 to 25 & 4 & $20.75-44.5$ \\
From -22.5 to 25 & 5 & $21.25-45$ \\
\hline
\end{tabular}

evaluation of blastability index for every rock mass structure type is given in Fig. 2, so as the rock mass is classified according to GSI and RMR systems, the exact BI range may be estimated. The relation of blastability index and powder factor led to the conclusion, the optimal design and explosive parameters may safely be calculated.

\subsection{BQS}

$\mathrm{BQS}$ is a very useful approach as it includes the most 
Table 2b BI calculations for closely spaced discontinuities.

\begin{tabular}{|c|c|c|c|}
\hline$\alpha / \alpha$ & RMD & JPS & JPO \\
\hline $701-720$ & 10 & 10 & 40 \\
\hline $721-740$ & 10 & 10 & 40 \\
\hline $741-760$ & 10 & 10 & 40 \\
\hline $761-780$ & 10 & 10 & 40 \\
\hline $781-800$ & 10 & 10 & 40 \\
\hline $801-820$ & 20 & 10 & 10 \\
\hline $821-840$ & 20 & 10 & 10 \\
\hline $841-860$ & 20 & 10 & 10 \\
\hline $861-880$ & 20 & 10 & 10 \\
\hline $881-900$ & 20 & 10 & 10 \\
\hline $901-920$ & 20 & 10 & 10 \\
\hline $921-940$ & 20 & 10 & 10 \\
\hline $941-960$ & 20 & 10 & 10 \\
\hline $961-980$ & 20 & 10 & 10 \\
\hline $981-1,000$ & 20 & 10 & 10 \\
\hline $1,001-1,020$ & 20 & 10 & 20 \\
\hline $1,021-1,040$ & 20 & 10 & 20 \\
\hline $1,041-1,060$ & 20 & 10 & 20 \\
\hline $1,061-1,080$ & 20 & 10 & 20 \\
\hline $1,081-1,100$ & 20 & 10 & 20 \\
\hline $1,101-1,120$ & 20 & 10 & 20 \\
\hline $1,121-1,140$ & 20 & 10 & 20 \\
\hline $1,141-1,160$ & 20 & 10 & 20 \\
\hline $1,161-1,180$ & 20 & 10 & 20 \\
\hline $1,181-1,200$ & 20 & 10 & 20 \\
\hline $1,201-1,220$ & 20 & 10 & 30 \\
\hline $1,221-1,240$ & 20 & 10 & 30 \\
\hline $1,241-1,260$ & 20 & 10 & 30 \\
\hline $1,261-1,280$ & 20 & 10 & 30 \\
\hline $1,281-1,300$ & 20 & 10 & 30 \\
\hline $1,301-1,320$ & 20 & 10 & 30 \\
\hline $1,321-1,340$ & 20 & 10 & 30 \\
\hline $1,341-1,360$ & 20 & 10 & 30 \\
\hline $1,361-1,380$ & 20 & 10 & 30 \\
\hline $1,381-1,400$ & 20 & 10 & 30 \\
\hline $1,401-1,420$ & 20 & 10 & 40 \\
\hline $1,421-1,440$ & 20 & 10 & 40 \\
\hline $1,441-1,460$ & 20 & 10 & 40 \\
\hline $1,461-1,480$ & 20 & 10 & 40 \\
\hline $1,481-1,500$ & 20 & 10 & 40 \\
\hline $1,501-1,520$ & 20 & 10 & 40 \\
\hline $1,521-1,540$ & 20 & 10 & 40 \\
\hline $1,541-1,560$ & 20 & 10 & 40 \\
\hline $1,561-1,580$ & 20 & 10 & 40 \\
\hline $1,581-1,600$ & 20 & 10 & 40 \\
\hline
\end{tabular}

\begin{tabular}{|c|c|c|c|}
\hline$\alpha / \alpha$ & SGI & $\mathrm{H}$ & $\mathrm{BI}$ \\
\hline $701-720$ & $22.5-25$ & 6 & $21.75-45.5$ \\
\hline $721-740$ & $22.5-25$ & 7 & $22.25-46$ \\
\hline $741-760$ & $22.5-25$ & 8 & $22.75-46.5$ \\
\hline $761-780$ & $22.5-25$ & 9 & $23.25-47$ \\
\hline $781-800$ & $22.5-25$ & 10 & $23.75-47.5$ \\
\hline $801-820$ & $22.5-25$ & 1 & $9.25-33$ \\
\hline $821-840$ & $22.5-25$ & 2 & $9.75-33.5$ \\
\hline $841-860$ & $22.5-25$ & 3 & $10.25-34$ \\
\hline $861-880$ & $22.5-25$ & 4 & $10.75-34.5$ \\
\hline $881-900$ & $22.5-25$ & 5 & $11.25-35$ \\
\hline $901-920$ & $22.5-25$ & 6 & $11.75-35.5$ \\
\hline $921-940$ & $22.5-25$ & 7 & $12.25-36$ \\
\hline $941-960$ & $22.5-25$ & 8 & $12.7-36.5$ \\
\hline $961-980$ & $22.5-25$ & 9 & $13.25-37$ \\
\hline $981-1,000$ & $22.5-25$ & 10 & $13.75-37.5$ \\
\hline $1,001-1,020$ & $22.5-25$ & 1 & $14.75-38$ \\
\hline $1,021-1,040$ & $22.5-25$ & 2 & $14.75-38.5$ \\
\hline $1,041-1,060$ & $22.5-25$ & 3 & $15.25-39$ \\
\hline $1,061-1,080$ & $22.5-25$ & 4 & $15.75-39.5$ \\
\hline $1,081-1,100$ & $22.5-25$ & 5 & $16.25-40$ \\
\hline $1,101-1,120$ & $22.5-25$ & 6 & $16.75-40.5$ \\
\hline $1,121-1,140$ & $22.5-25$ & 7 & $17.25-41$ \\
\hline $1,141-1,160$ & $22.5-25$ & 8 & $17.75-41.5$ \\
\hline $1,161-1,180$ & $22.5-25$ & 9 & $18.25-42$ \\
\hline $1,181-1,200$ & $22.5-25$ & 10 & $18.75-42.5$ \\
\hline $1,201-1,220$ & $22.5-25$ & 1 & $19.25-43$ \\
\hline $1,221-1,240$ & $22.5-25$ & 2 & $19.75-43.5$ \\
\hline $1,241-1,260$ & $22.5-25$ & 3 & $20.25-44$ \\
\hline $1,261-1,280$ & $22.5-25$ & 4 & $20.75-4.5$ \\
\hline $1,281-1,300$ & $22.5-25$ & 5 & $21.25-45$ \\
\hline $1,301-1,320$ & $22.5-25$ & 6 & $21.75-45.5$ \\
\hline $1,321-1,340$ & $22.5-25$ & 7 & $22.25-46$ \\
\hline $1,341-1,360$ & $22.5-25$ & 8 & $22.75-46.5$ \\
\hline $1,361-1,380$ & $22.5-25$ & 9 & $23.25-47$ \\
\hline $1,381-1,400$ & $22.5-25$ & 10 & $23.75-47.5$ \\
\hline $1,401-1,420$ & $22.5-25$ & 1 & $24.25-48$ \\
\hline $1,421-1,440$ & $22.5-25$ & 2 & $24.75-48.5$ \\
\hline $1,441-1,460$ & $22.5-25$ & 3 & $25.25-49$ \\
\hline $1,461-1,480$ & $22.5-25$ & 4 & $25.75-49.5$ \\
\hline $1,481-1,500$ & $22.5-25$ & 5 & $26.25-50$ \\
\hline $1,501-1,520$ & $22.5-25$ & 6 & $26.75-50.5$ \\
\hline $1,521-1,540$ & $22.5-25$ & 7 & $27.25-51$ \\
\hline $1,541-1,560$ & $22.5-25$ & 8 & $27.75-51.5$ \\
\hline $1,561-1,580$ & $22.5-25$ & 9 & $28.25-52$ \\
\hline $1,581-1,600$ & $22.5-25$ & 10 & $28.75-52.5$ \\
\hline
\end{tabular}


Table 3a RMR estimations for different types of rock mass with specific GSI range.

\begin{tabular}{lllllllllllll}
\hline \multirow{3}{*}{ GSI (part) } & A/A: & A/A: & A/A: & A/A: & A/A: & A/A: & A/A: & A/A: & A/A: & A/A: & A/A: & A/A: \\
& 001-80 & $81-140$ & $141-200$ & $201-280$ & $281-340$ & $341-400$ & $401-480$ & $481-540$ & $541-600$ & $601-680$ & $681-740$ & $741-800$ \\
\hline RMR & RMR & RMR & RMR & RMR & RMR & RMR & RMR & RMR & RMR & RMR & RMR \\
\hline B & $08-28$ & $09-29$ & $10-30$ & $03-28$ & $04-29$ & $05-30$ & $01-28$ & $002-29$ & $003-30$ & $011-33$ & $12-34$ & $13-35$ \\
C & $12-32$ & $13-33$ & $14-34$ & $07-32$ & $08-33$ & $09-34$ & $05-32$ & $006-33$ & $007-34$ & $15-37$ & $16-38$ & $17-39$ \\
D & $21-40$ & $22-41$ & $23-42$ & $16-40$ & $17-41$ & $18-42$ & $14-40$ & $15-41$ & $16-42$ & $24-45$ & $25-46$ & $26-47$ \\
E & $14-33$ & $15-34$ & $16-35$ & $09-33$ & $10-34$ & $11-35$ & $07-33$ & $008-34$ & $009-35$ & $17-38$ & $18-39$ & $19-40$ \\
F & $18-37$ & $19-38$ & $20-39$ & $13-37$ & $14-38$ & $15-39$ & $11-37$ & $012-38$ & $13-39$ & $21-42$ & $22-43$ & $23-44$ \\
G & $27-45$ & $28-46$ & $29-47$ & $22-45$ & $23-46$ & $24-47$ & $20-45$ & $21-46$ & $22-47$ & $30-50$ & $31-51$ & $32-52$ \\
H & $26-44$ & $27-45$ & $28-46$ & $21-44$ & $22-45$ & $23-46$ & $19-44$ & $20-45$ & $21-46$ & $29-49$ & $30-50$ & $31-51$ \\
\hline
\end{tabular}

Table 3b RMR estimations for different types of rock mass with specific GSI range.

\begin{tabular}{|c|c|c|c|c|c|c|c|c|c|c|c|c|}
\hline GSI (part) & $\begin{array}{l}\text { A/A: } \\
801-880\end{array}$ & $\begin{array}{l}\text { A/A: } \\
881-940\end{array}$ & $\begin{array}{l}\text { A/A: } \\
941-1,00 \\
0\end{array}$ & $\begin{array}{l}\text { A/A: } \\
1,001-1, \\
080\end{array}$ & $\begin{array}{l}\text { A/A: } \\
1,081-1, \\
140\end{array}$ & $\begin{array}{l}\text { A/A: } \\
1,141-1, \\
200\end{array}$ & $\begin{array}{l}\text { A/A: } \\
1,201-1, \\
280\end{array}$ & $\begin{array}{l}\text { A/A: } \\
1,281-1 \text {, } \\
340\end{array}$ & $\begin{array}{l}\text { A/A: } \\
1,341-1, \\
400\end{array}$ & $\begin{array}{l}\text { A/A: } \\
1,401-1, \\
480\end{array}$ & $\begin{array}{l}\text { A/A: } \\
1,481-1, \\
540\end{array}$ & $\begin{array}{l}\text { A/A: } \\
1,541-1, \\
600\end{array}$ \\
\hline & RMR & RMR & RMR & RMR & RMR & RMR & RMR & RMR & RMR & RMR & RMR & RMR \\
\hline I & $04-42$ & $11-50$ & $19-50$ & $0-40$ & $11-50$ & $14-50$ & $01-42$ & $004-50$ & $012-50$ & $007-47$ & $14-55$ & $22-55$ \\
\hline $\mathrm{J}$ & $06-44$ & $13-50$ & $21-52$ & $07-39$ & $13-52$ & $16-52$ & $01-44$ & $006-52$ & 014-52 & $009-46$ & $16-57$ & $24-57$ \\
\hline K & $19-50$ & $26-58$ & $24-58$ & $19-450$ & $21-58$ & $29-58$ & $12-50$ & $19-58$ & $27-58$ & $22-53$ & $31-63$ & $37-63$ \\
\hline $\mathrm{L}$ & $23-56$ & $30-64$ & $38-64$ & $23-56$ & $25-64$ & $33-64$ & $23-56$ & $23-69$ & $31-64$ & $26-61$ & $33-69$ & $41-69$ \\
\hline M & $27-58$ & $34-66$ & $42-66$ & $22-58$ & $29-66$ & $37-66$ & $20-58$ & $28-66$ & $35-66$ & $30-63$ & $37-71$ & $45-71$ \\
\hline $\mathrm{N}$ & $08-48$ & $15-60$ & $23-55$ & $03-47$ & $14-55$ & $18-55$ & $01-47$ & $008-55$ & $16-55$ & $011-52$ & $18-60$ & $26-61$ \\
\hline $\mathrm{O}$ & $10-52$ & $17-57$ & $25-57$ & $05-49$ & $12-57$ & $20-57$ & $03-49$ & $010-57$ & $18-57$ & $13-54$ & $20-62$ & $28-63$ \\
\hline $\mathrm{P}$ & $20-56$ & $27-61$ & $35-63$ & $15-55$ & $22-66$ & $30-63$ & $13-55$ & $20-63$ & $28-63$ & $31-63$ & $30-68$ & $38-69$ \\
\hline Q & $24-61$ & $31-69$ & $39-69$ & $19-61$ & $26-69$ & $34-69$ & $17-61$ & $24-69$ & $32-69$ & $27-65$ & $36-74$ & $42-75$ \\
\hline $\mathrm{R}$ & $28-63$ & $35-71$ & $43-71$ & $23-63$ & $30-71$ & $38-71$ & $21-63$ & $\begin{array}{l}28-29 \\
36-71\end{array}$ & $36-71$ & $31-68$ & $38-76$ & $46-76$ \\
\hline S & $12-57$ & $19-68$ & $27-65$ & $07-57$ & $18-65$ & $22-65$ & $05-57$ & $012-65$ & $20-65$ & $17-62$ & $22-70$ & $30-70$ \\
\hline $\mathrm{T}$ & $14-59$ & $21-67$ & $29-67$ & $09-59$ & $16-46$ & $24-67$ & $07-59$ & $14-67$ & $22-67$ & $17-58$ & $24-72$ & $32-72$ \\
\hline $\mathrm{U}$ & $20-64$ & $27-82$ & $35-72$ & $15-64$ & $22-72$ & $30-72$ & $08-64$ & $20-72$ & $28-72$ & $23-69$ & $30-77$ & $38-82$ \\
\hline V & $24-70$ & $31-78$ & $54-88$ & $19-70$ & $26-78$ & $34-78$ & $17-70$ & $24-78$ & $32-78$ & $27-75$ & $34-83$ & $42-83$ \\
\hline W & $28-72$ & $35-80$ & $43-80$ & $23-72$ & $30-75$ & $32-74$ & $21-52$ & $28-80$ & $36-80$ & $31-77$ & $38-80$ & $46-85$ \\
\hline
\end{tabular}

Table 4 GSI estimations for different types of rock mass with specific RMR range.

\begin{tabular}{lllll}
\hline \multirow{2}{*}{ RMR } & A/A 001-080 & A/A 081-140 & A/A 141-200 & A/A 201-280 \\
\cline { 2 - 5 } & BI: 4-29 & BI: 6-31 & BI: 7-32 & BI: 9-34 \\
\cline { 2 - 5 } & GSI (part) & GSI (part) & GSI (part) & GSI (part) \\
\hline $0-20$ & ABDE & ABCD & ABDE & ABCDE \\
$21-40$ & ABCDEFGH & ABDCEFGH & ABCDEFGH & ABCDEFGH \\
$41-60$ & FGH & CFGH & CFG & FGH \\
$61-80$ & & & & \\
$81-100$ & & & \\
\hline
\end{tabular}


Table 5 GSI estimations for different types of rock mass with specific RMR range.

\begin{tabular}{|c|c|c|c|c|c|c|c|c|}
\hline RMR & A/A: $801-880$ & A/A: $881-940$ & $\begin{array}{l}\text { A/A: } \\
941-1,000\end{array}$ & $\begin{array}{l}\text { A/A: } \\
1,001-1,080\end{array}$ & $\begin{array}{l}\text { A/A: } \\
1,081-1,140\end{array}$ & $\begin{array}{l}\text { A/A: } \\
1,141-1,200\end{array}$ & $\begin{array}{l}\text { A/A: } \\
1,201-1,280\end{array}$ & $\begin{array}{l}\text { A/A: } \\
1,281-1,340\end{array}$ \\
\hline & BI: 9-34 & BI: 11-36 & BI: $12-37$ & BI: 14-39 & BI: 16-41 & BI: $17-42$ & BI: 19-44 & BI: 21-46 \\
\hline $0-20$ & GSI (part) & GSI (part) & GSI (part) & GSI (part) & GSI (part) & GSI (part) & GSI (part) & GSI (part) \\
\hline $21-40$ & IJKNOPSTU & IJNOS & I & $\begin{array}{l}\text { IJKNOPQST } \\
\text { UV }\end{array}$ & IJNOST & IJNO & $\begin{array}{l}\text { IJKMNOPQS } \\
\text { TUV }\end{array}$ & IJKNOPSTU \\
\hline $41-60$ & $\begin{array}{l}\text { IJKLMNOPQ } \\
\text { RSTUVW }\end{array}$ & $\begin{array}{l}\text { IJKLMNOPQ } \\
\text { RSTUVW }\end{array}$ & $\begin{array}{l}\text { IJKLNOPQS } \\
\text { TU }\end{array}$ & $\begin{array}{l}\text { IJKLMNOPQ } \\
\text { RSTUVW }\end{array}$ & $\begin{array}{l}\text { IJKLMNOPQ } \\
\text { RSTUVW }\end{array}$ & $\begin{array}{l}\text { IJKLMNOPQ } \\
\text { RSTUVW }\end{array}$ & $\begin{array}{l}\text { IJKLMNOPQ } \\
\text { RSTUVW }\end{array}$ & $\begin{array}{l}\text { IJKLMNOPQ } \\
\text { RSTUVW }\end{array}$ \\
\hline $61-80$ & $\begin{array}{l}\text { IJKLMNOPQ } \\
\text { RSTUVW }\end{array}$ & $\begin{array}{l}\text { IJKLMNOPQ } \\
\text { RSTUVW }\end{array}$ & $\begin{array}{l}\text { IJKLMNOPQ } \\
\text { RSTUVW }\end{array}$ & $\begin{array}{l}\text { KLMNOPQR } \\
\text { STUVW }\end{array}$ & $\begin{array}{l}\text { IJKLMNOPQ } \\
\text { RSTUVW }\end{array}$ & $\begin{array}{l}\text { IJKLMNOPQ } \\
\text { RSTUVW }\end{array}$ & $\begin{array}{l}\text { IJKLMNOPQ } \\
\text { RSTUVW }\end{array}$ & $\begin{array}{l}\text { IJKLMNOPQ } \\
\text { RSTUVW }\end{array}$ \\
\hline $81-100$ & QRUVW & $\begin{array}{l}\text { LMPQRSTU } \\
\text { VW }\end{array}$ & $\begin{array}{l}\text { LMPQRSTU } \\
\text { VW }\end{array}$ & QRUVW & $\begin{array}{l}\text { LMPQRSUV } \\
\text { W }\end{array}$ & $\begin{array}{l}\text { LMPQRSTU } \\
\text { VW }\end{array}$ & QRUV & $\begin{array}{l}\text { LMPQRSTU } \\
\text { VW }\end{array}$ \\
\hline
\end{tabular}

Table 6 GSI estimations for different types of rock mass with specific RMR range.

\begin{tabular}{lllll}
\hline \multirow{2}{*}{ RMR } & A/A 1,341-1,400 & A/A 1,401-1,480 & A/A 1,481-1,540 & A/A 1,541-1,600 \\
\cline { 2 - 5 } & GSI (part) & GSI (part) & GSI (part) & GSI (part) \\
\hline $0-20$ & - & - & - & - \\
$21-40$ & - & - & - & - \\
$41-60$ & XY & XYZ & XY & - \\
$61-80$ & XYZ & XYZ & XYZ & XYZ \\
$81-100$ & XYZ & XYZ & XYZ & XYZ \\
\hline
\end{tabular}

useful characteristics of rock mass, which are easily estimated and used in situ. In addition to it is easy and wide use, it is a quick calculator for the BI and rock mass quality, which makes our choice of excavation, blast and support measures quicker.

The BI, calculated by Lilly (1986) [16] is used for the application of the new diagram (BQS). The diagram consists of surfaces with specific range of BI, which depends on discontinuities characteristics. The calculated BI ranges are optimized according to the GSI or RMR estimations. So, The BQS (Fig. 2) combines rock mass classification systems RMR and GSI with structural data and the BI [17]. The long excavated and tunnelling practice establishes the strong relation of the classification systems RMR and GSI. Also, the estimations of RMR and GSI for every possible rock mass type support this opinion. The RMR and GSI results were combined so as they can be estimated graphically.

At the first stage, the orientation of discontinuities is distinguished. At second stage, we can relate the structure to the surface conditions in order to estimate an area of RMR into diagrams. We can estimate the GSI using the gradient lines, too. Sometimes, we may use rock mass hardness (Mohs scale) [18] in order to estimate the exact area of GSI.

Having completed the above classification, the BI range can easily be determined at the left hand side of the diagram. Looking at rock structure, we can easily distinguish discontinuities in spacing and orientation. At the final stage we can relate the structure to the surface conditions in order to estimate GSI and RMR.

Taking into consideration the GSI and RMR estimations, we can come up with appropriate excavation technique and support measures [5, 11]. The ease of excavation, excavatability, has been related with RMR and GSI for the whole range of rockmass types. Although excavatability assessment includes also blasting ability, the already known literature does not estimate the blastability index at once. The ease of estimating the blastability index quickly is very useful in order to determine the required energy for fragmentation, the powder factor, and the explosive properties. Since the required information can be obtained from exploration drilling or from existing bench faces, the BQS can be used in both the planning and production phases of projects requiring rock blasting. When coupled with computerized fragmentation 


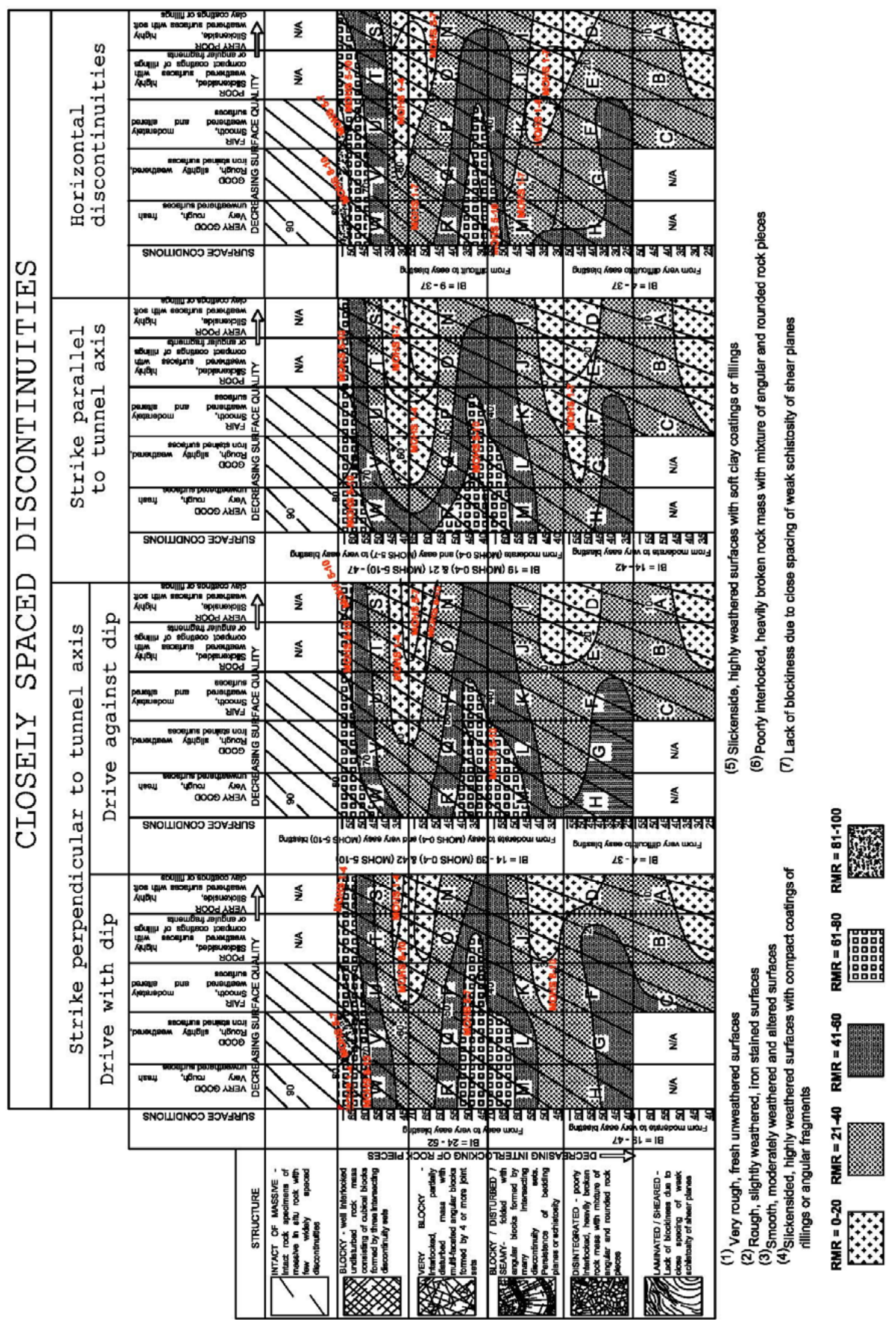

Fig. 2 BQS for closely spaced discontinuities. 
models, the blastability index can provide an excellent mean to experiment on the Visual Display Unit screen with a variety of blast designs, thereby avoiding expensive mistakes or miscalculations in the field.

\section{Discussion}

\subsection{In Situ Application of the Studied BQS Diagrams}

The first application refers to Asprovalta tunnel excavation works at Northern Greece where the rock mass consists of gneiss with pegmatitic veins. Looking at rock mass example in Fig. 4, the spacing discontinuities easily distinguished and characterized "closely" because of the presence of the schistosity. Using Fig. 2, the orientation of discontinuities may be determined. Looking again at Fig. 4, strike is parallel to tunnel axis. The discontinuous surfaces are smooth, moderately weathered and altered and the structure of the rock mass seems to be blocky and disturbed folded by many intersecting discontinuity sets. Relating the structure description and discontinuities surface condition description, the rock mass belongs to $\mathrm{K}$ part of the diagram (Fig. 3). Looking at left hand side of the diagram, the BI is between 19 and 47. That means blastability is moderate for soft rock masses and easy to very easy for medium and hard rock masses. Furthermore, GSI is estimating between 30 and 40 and also taking into consideration the RMR area, rock mass quality is usually classified as poor (RMR 21-40, category IV), although there are parts of very poor (V) and medium quality (III) rockmass (pegmatitic veins).

The second application refers to the works of a dam in Ikaria Island in Eastern Greece where the rock mass consists of gneiss. The spacing discontinuities distinguished and characterized "closely" (Fig. 5). Using Fig. 2, the orientation of discontinuities may be determined. Looking at Fig. 5, the discontinuities seem to be horizontal. The surfaces are slicken sided, highly weathered with compact coating of filling and the structure of rock mass is full of blockiness due to closely spaced weak schistosity of shear planes. Relating the structure description and discontinuities surface condition description, the rock mass belongs to B part of the diagram (Fig. 3). Looking at left hand side of the diagram, the BI is between 4 and 37 which means blasting is very difficult for soft rock mass and it becomes easier as the rock mass is hardening. Furthermore, GSI is estimating between 10 and 20. Taking into consideration the RMR area, rock mass quality is usually classified aspoor (RMR 21-40, category IV).

The third application refers to tunneling works of central-west Greece where the rock mass consists of gabbro. Looking at rock mass example in Fig. 6, the rock mass is cracked and the majority of discontinuities are "closely spaced". Using Fig. 2, the orientation of discontinuities may be determined. Looking again at Fig. 6, the strike of the main discontinuity system is perpendicular to tunnel axis and the excavation drives against dip direction. The surfaces are smooth, moderately weathered and altered and the structure of rock mass blocky formed by three intersecting discontinuity sets. Relating to the structure description and discontinuities surface condition description, the rock mass belongs to U part of the diagram (Fig. 3). Looking at left hand side of the diagram, the BI is between 13 and 39 , as the hardness of rock mass is estimated 2-4 MOHS. That means blasting is characterized moderate to easy. Furthermore, the GSI is estimating between 50 and 60 and also taking into consideration the RMR area, rock mass quality is usually classified as poor (RMR 21-40, category IV), but there are areas with very poor (RMR 0-20, category $\mathrm{V})$ and areas with medium quality (RMR 41-60, category III) rock mass. 


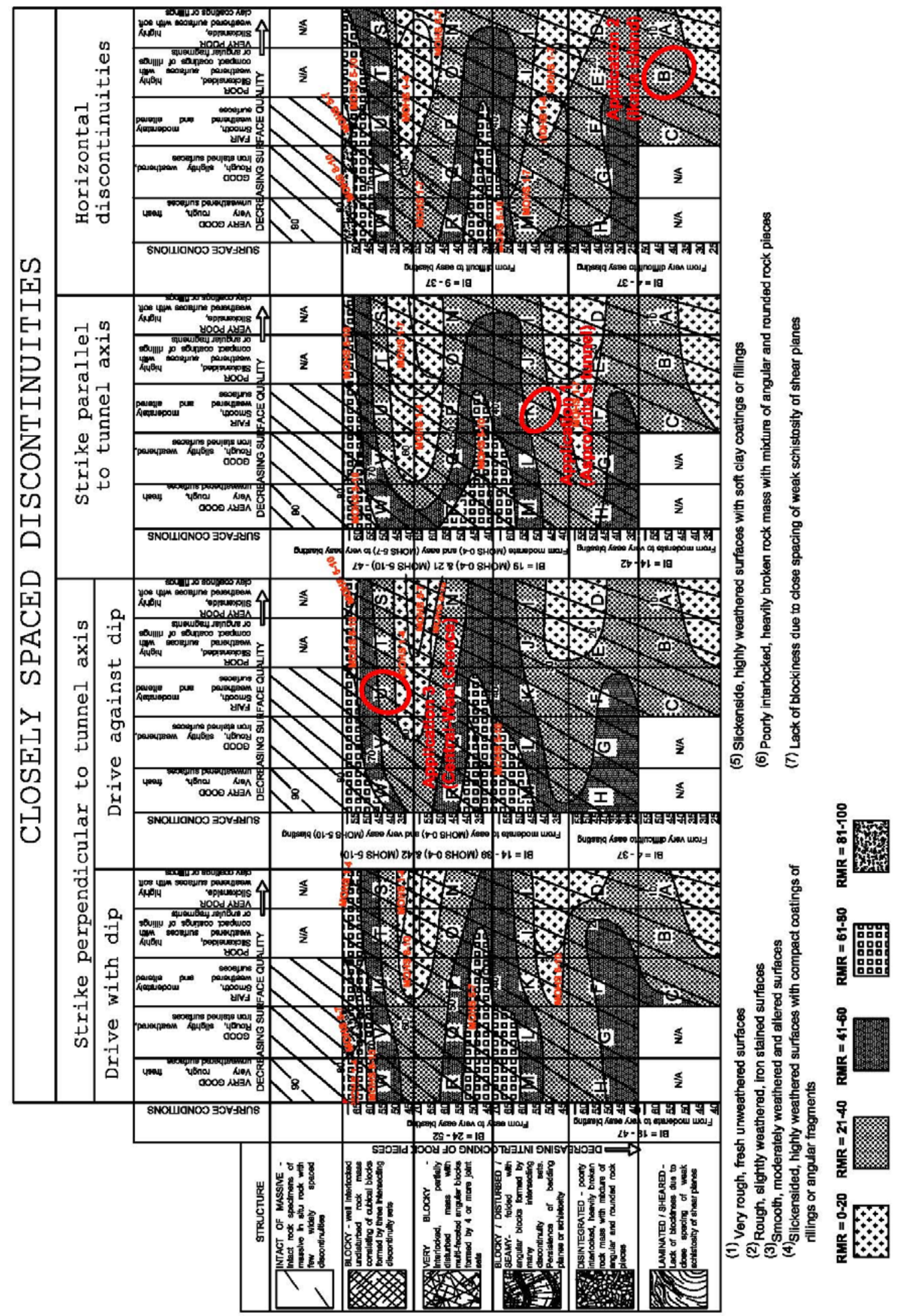

Fig. 3 Areas of estimation during application of the BQS for closely spaced discontinuities. 


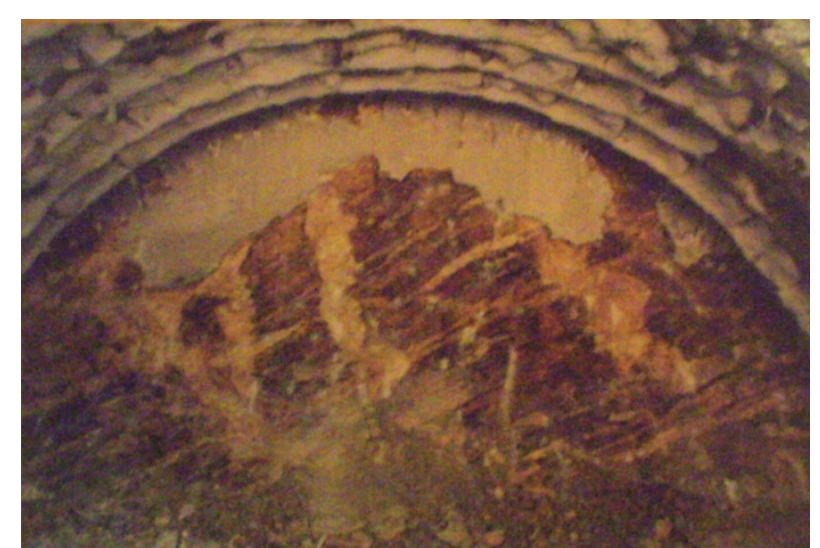

Fig. 4 Weathered and disintegrated rock mass quality at Asprovalta-Strymona's part of Egnatia Highway in Northern Greece.

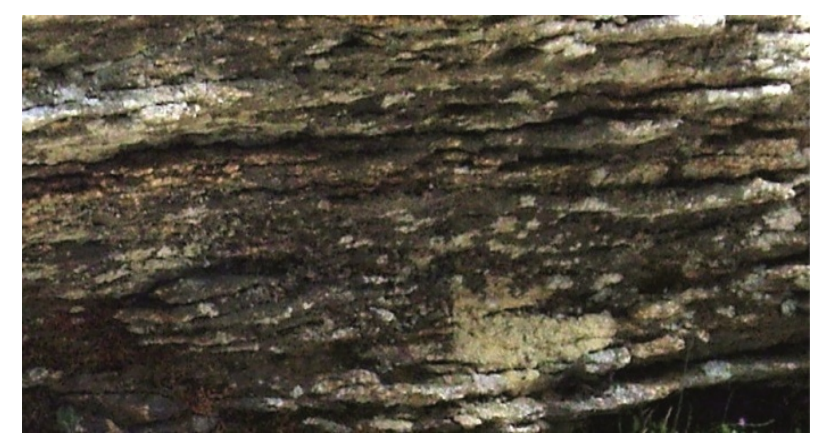

Fig. 5 Gneiss formation at Ikaria Island.

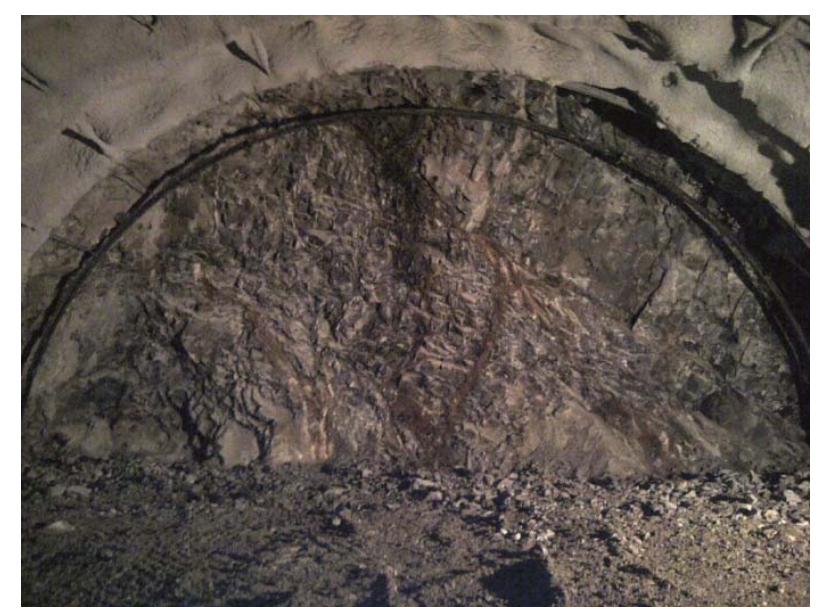

Fig. 6 Gabbro formation during tunneling works of central-west Greece.

\section{Conclusions}

The present paper improves the already known BQS for closely spaced discontinuities combining the quality with blast ability of rock mass, which can be easily used in situ, in order to estimate, quickly, the explosion results in relation to excavation methods.
"BQS" is a tool which combines rock mass quality, discontinuities orientation and rock mass hardness with the BI. It can be easily used during excavations, in order to estimate rock mass quality and the range of the BI very quickly and to describe the ease of rock mass blasting as

"very difficult", when the BI range is lower to 8 ,

"difficult", when the BI range is between 8 and 13,

"moderate", when the BI range is between 13 and 20 ,

"easy", when the BI range is between 20 and 40,

"very easy", when the BI range is higher than 40.

This is a great help for deciding on explosions and support measures, in addition to the already known methods. Three applications of the new system are described: the first one refers to the excavation works of Asprovalta's tunnel in Northern Greece where the rock mass consists of gneiss with pegmatitic veins; the second one refers to the study of a dam of Ikaria Island at Eastern Greece where the rock mass consists of gneiss; the third one refers to tunneling works of central-west Greece where the rock mass consists of gabbro. During the above applications, the rock mass blasting was characterized so as the engineers may provide blasting results or problems that may arise. Finally, the quality of the rock mass was classified by RMR and GSI systems, so as the engineers may suit the appropriate excavation technique and support measures by rock mass demands quickly.

\section{References}

[1] Chatziangelou, M., and Christaras, B. 2013. "Blastability Index on Poor Quality Rock Mass." Int. J. of Civil Engineering (IJCE) 2 (5): 9-16.

[2] Jimeno, C. L., Jinemo, E. L., and Carcedo, F. J. A. 1995. Drilling \& Blasting of Rock. Rotterdam, Netherlands: Brookfield Publication, 160-80.

[3] Murthy, V., and Raitani, R. 2003. "Prediction of Overbreak in Underground Tunnel Blasting. A Case Study." Journal of Canadian Tunneling Canadien: 109-15.

[4] Tsonos, A. 2014. "A New Method for Earthquake Strengthening of Old R/C Structures without the Use of Conventional Reinforcement." Structural Engineering 
and Mechanics 52 (2): 391-403.

[5] Bieniawski, Z. T. 1989. Engineering Rock Mass Classifications. New York: Wiley.

[6] Romana, M., Serón, J. B., and Montalar, E. 2003. "SMR Geomechanics Classification: Application, Experience and Validation." In ISRM 2003-Technology Roadmap for Rock Mechanics. Johannesburg: South African Institute of Mining and Metallurgy.

[7] Palmstrom, Ar. 2009. "Combining the RMR, Q and RMI Classification Systems." Tunnelling and Underground Space Technology 24 (4): 491-2.

[8] Hoek, E., Kaiser, P. K., and Bawden, W. F. 1995. Support of Underground Excavations in Hard Rock. Rotterdam, Netherlands: A. A. Balkema.

[9] Palmstrom, Ar. 2000. "Recent Developments in Rock Support Estimates by the RMI." J Rock Mech. Tunnel Techn 6 (1): 1-19.

[10] Sonmez, H., and Ulusay, R. 1999. "Modifications to the Geological Strength Index (GSI) and Their Applicability to Stability of Slopes." Int J Rock Mech Min Sci 36: 743-60.

[11] Cai, M., Kaiser, P. K., Uno, H., Tasaka, Y., and Minami, M. 2004. "Estimation of Rock Mass Deformation Modulus and Strength of Jointed Hard Rock Masses Using the GSI System." International Journal of Rock Mechanics and Mining Sciences 41 (1): 3-19.

[12] Hoek, E., and Karzulovic, A. 2000. "Rock Mass Properties for Surface Mines." In Slope Stability in Surface Mining, edited by Hustralid, W. A., McCarter, M. K., and van Ayl, D. J. A. Littleton, Colorado: Society for Mining, Metallurgical and Exploration (SME), 59-70.

[13] Latham, J. P., and Ping, L. 1999. "Development of a Assessment System for the Blastability of Rock Masses." International Journal of Rock Mechanics and Mining Sciences 36: 41-55.

[14] Singh, P., and Sinha, Am. 2012. Rock Fragmentation by Blasting. Taylor \& Francis: CRC Press.

[15] Kaushik, D., and Phalguni, S. 2003. "Concept of Blastability-An Update." The Indian Mining \& Engineering Journal 42 (8 \& 9): 24-31.

[16] Lilly, P. 1986. "An Empirical Method of Assessing Rock Mass Blastability." In Proceedings of the Large Open Pit Mine Conference, 89-92.

[17] Hino, K. 1959. Theory and Practice of Blasting. Noppon Kayaku Co. Ltd.

[18] Mohs, F. 1812. Versucheiner Elementar-Methodezur Naturhistorischen Bestimmung und Erkennung von Fossilie. Österreich Lexikon. 